A Lukács, K Mayer, A Török, E Kiss-Tóth, L Barkai: Better cardiorespiratory fitness associated with favourable metabolic control and health-related quality of life in youths with type 1 diabetes mellitus. Acta Physiologica Hungarica, 100 (1), pp. 77-84 (2013)

DOI: 10.1556/APhysiol.100.2013.1.7

\title{
Better cardiorespiratory fitness associated with favourable metabolic control and health-related quality of life in youths with type 1 diabetes mellitus
}

\author{
A Lukács ${ }^{1}$, K Mayer $^{1}$, A Török ${ }^{2}$, E Kiss-Tóth $^{1}$, L Barkai $^{1,2,3}$ \\ ${ }^{1}$ Faculty of Health Care, University of Miskolc, Miskolc, Hungary \\ ${ }^{2}$ Borsod-Abaúj-Zemplén County and University Hospital, Miskolc, Hungary \\ ${ }^{3}$ Postgraduate Institute of Pediatrics, Medical and Health Science Center, University of \\ Debrecen, Debrecen, Hungary
}

\begin{abstract}
Objective: to explore the relationship among health-related quality of life (HRQoL), clinical variables, anthropometric measures, physical activity and cardiorespiratory fitness in children and adolescents with type 1 diabetes. Furthermore, we aimed to find predictors of HRQoL and metabolic control. Methods: A total of 106 patients (sex ratio: 1:1) with mean $\mathrm{HbA} 1 \mathrm{c}$ of $8.55( \pm 1.44) \%$ and diabetes duration of $5.15( \pm 3.24)$ years were assessed. The average age was $13.22( \pm 3.08)$ years. Results: We observed statistically significant negative medium correlation between $\mathrm{HbA}_{1 \mathrm{c}}$ and $\mathrm{VO}_{2 \max }(\mathrm{r}=-0.343 ; \mathrm{p}<0.001)$. There was statistically significant small positive correlation between the HRQoL and the maximal oxygen consumption $(r=0.208 ; p=0.032)$. We found no significant correlation between the $\mathrm{HbA}_{1 \mathrm{c}}$ and the patients' HRQoL. In the multiple linear regression analysis both the better metabolic control and the HRQoL was predicted by the $\mathrm{VO}_{2 \max }$, other variables had no effect. Physical activity level did not explain the HRQoL. Boys had significantly better HRQoL and less skinfold thickness than girls. Conclusion: Better cardiorespiratory fitness associated with both favourable metabolic control and better HRQoL of diabetic youths. Regular aerobic exercise improves the young patients' physical fitness and overall health status, and perception of health-related quality of life, respectively.
\end{abstract}

Keywords: type 1 diabetes, metabolic control, health-related quality of life, cardiorespiratory fitness, physical activity 
Type 1 diabetes mellitus (T1DM) is one of the commonest chronic diseases in childhood affecting more and more children worldwide (6). The diabetes care is complex and it takes continuous management from the healthcare experts, caregivers and from the patients. Treatment for T1DM involves the continual use of insulin therapy with appropriate diet and regular physical exercise. The main goal of the diabetes management is to maintain the blood glucose level in the near-normal range in order to prevent the long-term complications. Attention has shifted from treatment to improving overall health condition. The health-related quality of life (HRQoL) is the person's own perceived state of health. It has been recognised as an important paediatric outcome measurement. We observed controversial results regarding the HRQoL and metabolic control in the literature. Some studies found positive correlation between better HRQoL and good glycemic control $(12,14,28)$, others had no evidence about it $(7,9,17)$. Physical activity is essential to health in people of all ages, but for children plays a key role for their physical and mental health. The regular exercise in diabetes management is part of the treatment. It is recommended primary for patients with type 2 diabetes, but it can be safe and rewarding experience for the great majority of children and adolescents with T1DM (1). It enhances insulin sensitivity, reduces cardiovascular risk, increases cardiorespiratory fitness, improves glycemic control. There are some evidences that cardiorespiratory fitness is reduced in youths with T1DM compared to healthy peers $(21,29)$, but limited data exist regarding physical fitness in type 1 diabetic children and adolescents. Majority of diabetics avoid physical activity mainly because of the fear of exercise-induced hypoglycaemia and its severe consequences including loss of consciousness (5), but it can be controlled with careful monitoring of blood glucose level and supervising by healthcare providers (8) The regular exercise especially aerobic exercise is important for reducing the cardiovascular morbidity and mortality (2-4). The best quantitative measure of cardiorespiratory fitness is maximal oxygen consumption, expressed as $\mathrm{VO}_{2 \max }$, the amount of oxygen the body uses when a person reaches maximum ability to supply oxygen during exercise.

The purpose of our cross-sectional study was to explore the relationship among the diabetes-specific HRQoL, clinical variables, anthropometric measures, level of physical activity and cardiorespiratory fitness (expressed by VO2max) in children and adolescents with T1DM. Furthermore, we assessed the predictors of HRQoL and metabolic control from the variables of age, gender, diabetes duration, body composition, physical activity and cardiorespiratory fitness.

\section{Patients and Methods \\ Study participants}

The sample consisted of 106 patients with type 1 diabetes (53 girls and 53 boys). Their age ranged from 8 to 18 with an average of 13.22 years $(S D=3.08), 13.15$ years $(S D=3.10)$ for females and 13.29 years $(\mathrm{SD}=3.09)$ for males. Glycated haemoglobin in the sample was, in average, $8.55 \%(\mathrm{SD}=1.44)$ specifically $8.72 \%(\mathrm{SD}=1.31)$ for girls and $8.38 \%(\mathrm{SD}=1.56)$ for boys, respectively. Average diabetes duration was $5.15(\mathrm{SD}=3.24)$ years with girls being diagnosed for $5.29(\mathrm{SD}=2.80)$ years and boys for $5.02(\mathrm{SD}=3.65)$ years $($ Table $\mathrm{I})$.

The diabetic participants were from the Pediatric Diabetes Center of the Borsod-AbaújZemplén County University Hospital, Miskolc representing the northern-east region of the country. The patients had been diagnosed with type 1 diabetes at least 1 year; and had no diabetes complications by regular assessments for retinopathy (fundal photography), nephropathy (microalbuminuria) and neuropathy (nerve conduction velocity and cardiovascular reflex tests). Table 1 presents the characteristics of the study participants by gender. 
The parents and the youths were informed about the purpose and the method of the survey verbally and in written form. The parents and youths over 18 gave written consent; the children and adolescents gave their assent before the completion of the study.

The study was approved by the Borsod-Abaúj-Zemplén County Regional Scientific and Research Ethics Committee.

\section{Pediatric Quality of Life Inventory 3.0 Diabetes Module}

The young patients completed the Pediatric Quality of Life Inventory ${ }^{\mathrm{TM}} 3.0$ Diabetes Module. This instrument is a disease-specific module and includes 28 items with 5 subscales /diabetes symptoms (11 items), treatment barriers (4 items), treatment adherence ( 7 items), worry (3 items) and communication (3 items)/. Participants had to rate how much of a problem of each item of the questionnaire have been in the previous month on a five-point Likert scale. Five categories were used, ranging from never a problem (0) to almost always a problem (4). All the items were transformed to a 0-100 scale. The higher score represented better quality of life (27). The 3.0 Diabetes Module has been validated for Hungarian usage (20).

\section{Physical activity}

The Physical Activity Questionnaire for Older Children (PAQ-C) and the Physical Activity Questionnaire for Adolescents (PAQ-A) were used to assess physical activity levels of the patients $(15,16)$. These tests are self-administered, 7-day recall questionnaires that provide general measure of physical activity for youths from ages 8-19. They classify children and adolescents into five different activity levels. A score of 1 indicates low physical activity, whereas a score of 5 indicates high physical activity.

\section{Assessment of cardiorespiratory fitness}

The maximal oxygen consumption was estimated from the 20 metre shuttle run test. The test involves continuous running between two lines $20 \mathrm{~m}$ apart in time to recorded beeps. The initial running speed is $8.5 \mathrm{~km} / \mathrm{hr}$, which increases by $0.5 \mathrm{~km} / \mathrm{hr}$ each minute. The participant has to keep pace with the beep sound as long as possible. When the runner could no longer follow the pace and reach the 20 meter line consecutively twice with the beep, the last stage announced by the tape recorder was used to predict the $\mathrm{VO}_{2 \max }$ using Léger et al. regression equation (18). The validity of the test in prediction of maximal oxygen consumption has been previously established $(19,24)$. The shuttle run test was carried out 08.00-10.00 AM and if morning home blood glucose result of the patient was out of the target range $(5-10 \mathrm{mmol} / \mathrm{l})$, a new appointment was given to perform the test on other day.

\section{Metabolic control}

Latest $\mathrm{HbA}_{1 \mathrm{c}}$ values extracted from medical records were used to estimate metabolic control of the patients.

\section{Anthropometric assessment}

Skinfold thickness was measured at four sites (triceps, biceps, subscapular and suprailiac) on the right side of the body using Harpenden skinfold calliper (HSB-BI, British Indicators Ltd., 80 UK) according to the International Society for the Advancement Kinanthropometry (22). Two non-consecutive measurements for all sites were performed and mean values were used for data analysing. As there is no gold standard to evaluate the body fat content in percentage for children and adolescents the skinfold thickness was summed in $\mathrm{mm}$. Height (to the nearest $0.5 \mathrm{~cm}$ ) and weight (accurate to $0.1 \mathrm{~kg}$ ) in light clothing without shoes were measured to calculate the body mass index $(\mathrm{kg} / \mathrm{m} 2)$. Each BMI value was standardized by conversion to a 
z-score (BMI z-score) defined by age and gender using the Hungarian National Institute of Child Health Chart (13).

\section{Statistical analysis}

SPSS 19.0 software was used for data analysis. Data are presented as mean and \pm standard deviation (SD), p-value at $\leq 0.05$ was considered significant. Pearson and Spearman correlations were used to assess associations as appropriate, and multiple regression analysis was used to determine significant independent predictors of the HRQoL and the metabolic control from the variables of age, gender, diabetes duration, skinfold thickness, BMZ z-score, physical activity level and maximal oxygen consumption. Gender differences in these variables were explored with independent t-test and Chi-square test.

\section{Results}

In our sample diabetic participants had HRQoL scores between 37.04 and 99.07. The mean score was $70.20 \pm 12.61$. There was a significant effect for gender $(\mathrm{p}=0.046)$, with boys having higher scores than girls. (Fig. 1)

We observed significant gender differences in maximal oxygen consumption (boys: $41.96 \pm$ 5.57 vs. girls $38.30 \pm 6.73 ; \mathrm{p}=0.003$ ), and in skinfold thickness (boys: $57.28 \pm 25.57$ vs. girls: $77.01 \pm 29.56$; $<<0.001$ ); but it was not the case in age, diabetes duration, BMI z-score, physical activity and metabolic control.

There was statistically significant negative medium correlation between the metabolic control and the maximal oxygen consumption ( $\mathrm{r}=-0.343$; $\mathrm{p}<0.001)$ (Fig. 2) and weak positive correlation between the HRQoL and the maximal oxygen consumption $(r=0.208 ; p$ $=0.032$ ). We found no significant correlation between the $\mathrm{HbA}_{1 \mathrm{c}}$ and the patients' HRQoL.

In the multiple linear regression analysis the better metabolic control was predicted by the $\mathrm{VO}_{2 \max }\left(\mathrm{B}=-0.077, \mathrm{SE}(\mathrm{B})=0.021, \beta=-0.343, \mathrm{t}=-3.726, \mathrm{p}<0.001, \mathrm{R}=0.343, \mathrm{R}^{2}=0.118\right)$ other variables had no effect. When we examined the independent contributions of age, gender, diabetes duration, BMI z-score, skinfold thickness, metabolic control, physical activity level and maximal oxygen consumption on diabetes-specific HRQoL, significant predictor was likewise the maximal oxygen consumption $(\mathrm{B}=0.522, \mathrm{SE}(\mathrm{B})=0.194, \beta=-$ $0.266, \mathrm{t}=-2.700, \mathrm{p}=0.008, \mathrm{R}=0.286, \mathrm{R}^{2}=0.082$ ).

\section{Discussion}

In the last decades, the management of type 1 diabetes has improved, with better metabolic control and reduction of long-term complications. It seems that children can live happy life as their healthy peers; however quality of life data are controversial. While there is a growing interest in quality of life issues in diabetes, it is important to identify which variables predict better outcomes. For this reason we examined the relationship among the HRQoL, clinical parameters (age, glycated haemoglobin and duration of disease), body composition (skinfold thickness and BMI z-score), physical activity, cardiorespiratory fitness (expressed by $\mathrm{VO}_{2 \max }$ ) in children and adolescents with type 1 diabetes.

HRQoL and body compositions had no relationship in our study similar to Naughton's result (23). It is known that the overweight is associated with decreased HRQoL perception (25). Our diabetic patients were in normal BMI range, although there was notable gender difference in skinfold thickness. Females have greater skinfold thickness than males, that is typical for the normal pediatric population as well (26). When we compared the youths'

HRQoL by gender, we found that boys had better perception of quality of life than girls. This gender difference was confirmed in Graue and Kalyva' researches $(9,14)$. We did not find significant relationship between the HRQoL and the metabolic control. The quality of life is the person's subjective opinion about his or her well-being and health status; and sometimes 
there is no close association between HRQoL and the severity of the disease. Our finding is congruent with Grey's and Hoare's study where no relationship was found between glycemic control, as measured by $\mathrm{HbA}_{1 \mathrm{c}}$, and diabetes-specific quality of life $(10,11)$. We measured both the physical activity and the maximal oxygen consumption. Most studies found significant association between the physical activity and the HRQoL. In our study the physical activity had no effect on HRQoL. There might be several reasons. We measured the physical activity using questionnaire that might be subjective; and it did not give information on the intensity of exercise. Physical activity generally refers to movement that enhances health condition, but not the type and intensity of exercise. Physical fitness is considered one of the most important health markers. $\mathrm{VO}_{2 \max }$ is the best indicator of the person's actual fitness status. The higher maximal oxygen consumption correlated with better metabolic control and HRQoL. The better cardiorespiratory fitness explained both the favourable metabolic control and the better quality of life in children and adolescents with type 1 diabetes mellitus in the regression model.

Strength of our study is that we approached the HRQoL in addition to the physical activity level and cardiorespiratory fitness. Findings are important because they suggest that the physical fitness is essential to maintain good metabolic control; assessment of physical activity is not necessarily powerful marker of health status.

Limitation of our study is that we assessed youths from one pediatric centre with relatively small sample size. Self-report physical activity is also a limitation; the questionnaire has been validated in the original population, but not in Hungarian youths. The $20 \mathrm{~m}$ shuttle run test is indirect measure of the maximal oxygen consumption. These limitations reduce the possibility to generalize the results.

\section{Conclusion}

Metabolic control and HRQoL are two important outcomes of diabetes management. We suggest healthcare experts to take into consideration in the treatment and care of diabetes that regular aerobic exercise improves the young diabetic patients' physical fitness and overall health status, and perception of HRQoL, respectively.

\section{Acknowledgements}

We are very grateful to all diabetes patients for taking part in this research study. We would like to thank the physicians and assistants of the Pediatric Diabetes Center of the BorsodAbaúj-Zemplén County University Hospital for their interest and co-operation. This research work was carried out as part of the TAMOP-4.2.1.B-10/2/KONV-2010-0001 project with support by the European Union, co-financed by the European Social Fund. Andrea Lukács was granted by the Hungarian Diabetes Association.

\section{REFERENCES}

1. American Diabetes Association: Physical activity/exercise and diabetes mellitus. Position Statement. Diabetes Care 26 (Suppl. 1), S73-S77 (2003)

2. Apor P: A cukorbetegség javítása testmozgással. Háziorv. Tképző Szemle, 5, 60-63 (2000)

3. Apor P: Fizikai edzés a cukorbetegeség megelőzésében és kezelésében. Orv. Hetil. 150, 579-587 (2009)

4. Birrer RB, Sedaghat VD: Training in diabetes 1. Phys. Sportsmed. 31, 29-35 (2003)

5. Brazeau AS, Rabasa-Lhoret R, Strychar I, Mircescu H: Barriers to physical activity among patients with type 1 diabetes. Diabetes Care 31, 2108-2109 (2008)

6. Daneman D: Type 1 diabetes. The Lancet 367, 847-858 (2006) 
7. Emmanouilidou E, Galli-Tsinopoulou A, Karavatos A, Nousia-Arvanitakis S: Quality of life of children and adolescents with diabetes of Northern Greek origin. Hippokratia 12, 168 175 (2008)

8. Giannini C, Mohn A, Chiarelli F: Physical exercise and diabetes during childhood. Acta Biomed. Ateneo Parmense 77 (Suppl. 1), 18-25 (2006)

9. Graue M, Wentzel-Larsen T, Hanestad BR, Båtsvik B, Søvik O: Measuring self-reported, health-related, quality of life in adolescents with type 1 diabetes using both generic and disease-specific instruments. Acta Paediatr. 92, 1190-1196 (2003)

10. Grey M, Boland EA, Davidson M, Yu C, Sullivan-Bolyai S, Tamborlane WV: Short-term effects of coping skills training as adjunct to intensive therapy in adolescents. Diabetes Care 21, 902-908 (1998)

11. Hoare P, Mann H, Dunn S: Parental perception of the quality of life among children with epilepsy or diabetes with a new assessment questionnaire. Qual. Life Res. 9, 637-644 (2000) 12. Hoey H, Aanstoot HJ, Chiarelli F, Daneman D, Danne T, Dorchy H, Fitzgerald M, Garandeau P, Greene S, Holl R, Hougaard P, Kaprio E, Kocova M, Lynggaard H, Martul P, Matsuura N, McGee HM, Mortensen HB, Robertson K, Schoenle E, Sovik O, Swift P, Tsou RM, Vanelli M, Aman J: Good metabolic control is associated with better quality of life in 2101 adolescents with type 1 diabetes. Diabetes Care 24, 1923-1928 (2001)

13. Hungarian National Institute of Child Health. Available from: http://www.ogyei.hu/upload/files/gyermekkoriTaplaltsag.pdf [Accessed March 22, 2012] 14. Kalyva E, Malakonaki E, Eiser C, Mamoulakis D: Health-related quality of life (HRQL) of children with type 1 diabetes mellitus (T1DM): self and parental perceptions. Pediatr.

Diabetes 12, 34-40 (2011)

15. Kowalski KC, Crocker PRE, Faulkner RA: Validation of the physical activity questionnaire for older children. Pediatr. Exerc. Sci. 9, 174-186 (1997)

16. Kowalski CK, Crocker PRE, Kowalski NP: Convergent validity of the physical activity questionnaire for adolescents. Pediatr. Exerc. Sci. 9, 342-352 (1997)

17. Laffel LM, Connell A, Vangsness L, Goebel-Fabbri A, Mansfield A, Anderson BJ: General quality of life in youth with type 1 diabetes: relationship to patient management and diabetes-specific family conflict. Diabetes Care 26, 3067-3073 (2003)

18. Léger LA, Mercier D, Gadoury C, Lambert J: The multistage 20 metre shuttle run test for aerobic fitness. J. Sports Sci. 6, 93-101 (1988)

19. Liu NY, Plowman SA, Looney MA: The reliability and validity of the 20-meter shuttle test in American students 12 to 15 years old. Res. Q. Exerc. Sport 63, 360-365 (1992)

20. Lukács A, Varga B, Barótfi Sz, Kiss-Tóth E, Barkai L: Health-related quality of life of youths with type 1 diabetes: reliability and validity of the Hungarian version of the PedsQL 3.0 Diabetes Module. J. Diabetes Metab. 3:191.

21. Maggio AB, Hofer MF, Martin XE, Marchand LM, Beghetti M, Farpour-Lambert NJ:

Reduced physical activity level and cardiorespiratory fitness in children with chronic diseases.

Eur. J. Pediatr. 169, 1187-1193 (2010)

22. Marfell-Jones M (2006): International standards for anthropometric assessment. 2nd edn.

Potchefstroom, South Africa: International Society for the Advancement of

Kinanthropometry, pp. 57-66

23. Naughton MJ, Ruggiero AM, Lawrence JM, Imperatore G, Klingensmith GJ, Waitzfelder B, McKeown RE, Standiford DA, Liese AD, Loots B; SEARCH for Diabetes in Youth Study Group: Health-related quality of life of children and adolescents with type 1 or type 2 diabetes mellitus. Arch. Pediatr .Adolesc. Med. 162, 649-657 (2008)

24. Ramsbottom R, Brewer J, Williams C: A progressive shuttle run test to estimate maximal oxygen uptake. Br. J. Sports Med. 22, 141-144 (1988) 
25. Tsiros MD, Olds T, Buckley JD, Grimshaw P, Brennan L, Walkley J, Hills AP, Howe PR, Coates AM: Health-related quality of life in obese children and adolescents. Int. J. Obes. 33, 387-400 (2009)

26. Ulijaszek SJ, Johnston FE, Preece MA (edited) (1998): The Cambridge Encyclopedia of Human Growth and Development, Cambridge University Press, United Kingdom, pp. 214 27. Varni JW, Burwinkle TM, Jacobs JR, Gottschalk M, Kaufman F, Jones KL: The PedsQL in type 1 and type 2 diabetes: reliability and validity of the Pediatric Quality of Life Inventory Generic Core Scales and type 1 diabetes Module. Diabetes Care 26, 631-637 (2003)

28. Wagner VM, Müller-Godeffroy E, von Sengbusch S, Häger S, Thyen U: Age, metabolic control and type of insulin regime influences health-related quality of life in children and adolescents with type 1 diabetes mellitus. Eur. J. Pediatr. 164, 491-496 (2005)

29. Williams BK, Guelfi KJ, Jones TW, Davis EA: Lower cardiorespiratory fitness in children with type 1 diabetes. Diabet. Med. 28, 1005-1007 (2011) 
Table I. Characteristics of the diabetic participants by gender

\begin{tabular}{|l|c|c|c|}
\hline \multicolumn{1}{|c|}{ Mean, standard deviation $( \pm)$} & Girls & Boys & $p$-value \\
\hline Sample size & 53 & 53 & \\
\hline Age (years old) & $13.15( \pm 3.10)$ & $13.29( \pm 3.09)$ & 0.810 \\
\hline Diabetes duration (years) & $5.29( \pm 2.80)$ & $5.02( \pm 3.65)$ & 0.669 \\
\hline HbA1c (\%) & $8.72( \pm 1.31)$ & $8.38( \pm 1.56)$ & 0.227 \\
\hline BMI z-score & $0.66( \pm 0.78)$ & $0.38( \pm 1.02)$ & 0.118 \\
\hline Skinfold thickness (mm) & $77.01^{\circ}( \pm 22.99)$ & $57.28^{\circ}( \pm 25.57)$ & $0.000^{*}$ \\
\hline
\end{tabular}

${ }^{*} p \leq 0.001$
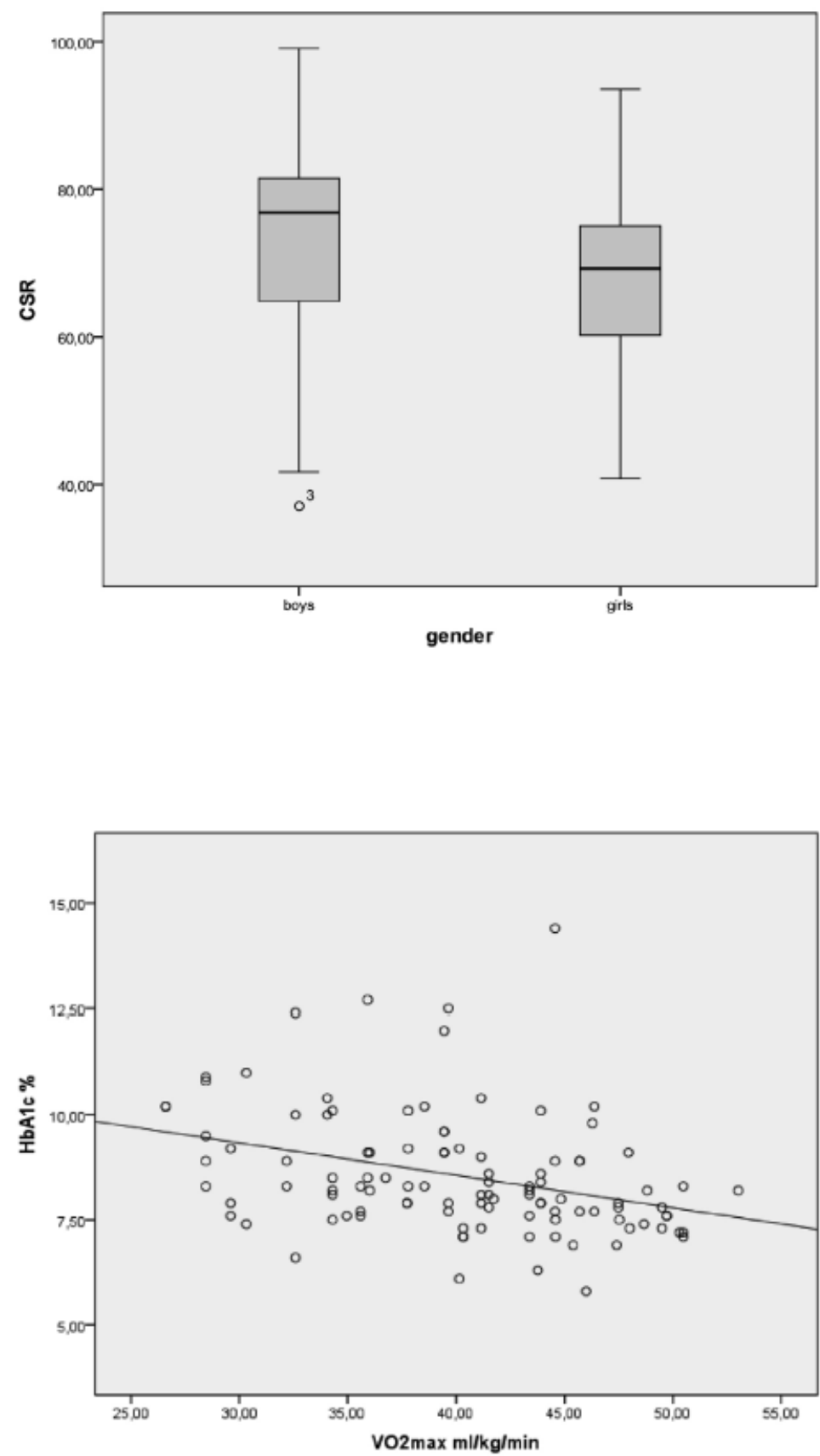

Fig. 1. Diabetic participants' HRQoL by gender (according to the Pediatric

Quality of Life Inventory 3.0

Diabetes Module child self-report).

Boys: $72.64( \pm 12.64)$ vs.

Girls: $67.77( \pm 12.02) ; p \leq 0.046$
Fig. 2. Scatter plot of the correlation between $\mathrm{HbAlc}$ and $\mathrm{VO}_{2 \max }$ $(r=-0.343 ; p=0.000)$ 